Aletheia

ISSN: 1853-3701

publicaciones@fahce.unlp.edu.ar

Universidad Nacional de La Plata

Argentina

\title{
Orígenes y consolidación de la Asociación Madres de Plaza de Mayo de Mar del Plata (1976-1989). Tesis de Maestría en Historia y Memoria
}

\author{
Zubillaga, Paula \\ Orígenes y consolidación de la Asociación Madres de Plaza de Mayo de Mar del Plata (1976-1989). Tesis \\ de Maestría en Historia y Memoria \\ Aletheia, vol. 10, núm. 19, 2019 \\ Universidad Nacional de La Plata, Argentina \\ DOI: https://doi.org/10.24215/18533701e040
}

Esta obra está bajo una Licencia Creative Commons Atribución-NoComercial-Compartirlgual 4.0 Internacional. 


\section{Orígenes y consolidación de la Asociación Madres de Plaza de Mayo de Mar del Plata (1976-1989). Tesis de Maestría en Historia y Memoria}

Paula Zubillaga

DOI: https://doi.org/10.24215/18533701e040

Universidad Nacional de General Sarmiento/CONICET,

Argentina

paulazubillaga@gmail.com

¿Cómo fue el surgimiento y el desarrollo del movimiento de derechos humanos fuera del ámbito capitalino? ¿Fue un actor de relevancia en otras localidades? ¿En qué ciudades y por qué se conformaron filiales de organizaciones nacidas en la Capital Federal y en cuáles y por qué se formaron agrupaciones netamente locales defensoras de los derechos humanos? ¿Cuál es el grado de autonomía/dependencia que han mantenido? ¿Qué las ha definido como "filiales"? ¿Han recibido directivas político-ideológicas y/o apoyo económico? ¿Cuáles fueron los modos de organización y acción en las distintas geografías? ¿Qué vínculo se estableció entre las organizaciones de la Capital Federal y las nacidas en otras localidades? ¿La conjunción de historias locales o regionales supone una historia nacional del movimiento? ¿Qué aportan los estudios realizados a escala local? Estas fueron algunas de las preguntas iniciales que nos llevaron a realizar una tesis que analizara los orígenes del movimiento de derechos humanos en la ciudad de Mar del Plata (provincia de Buenos Aires), haciendo foco en la filial de la Asociación Madres de Plaza de Mayo, conformada en 1984. Consideramos que intentar responder esas preguntas permitía comprender mejor algunas lógicas al interior del movimiento de derechos humanos, como la construcción de liderazgos, la expansión territorial de las organizaciones, la configuración de redes y de alianzas, los posicionamientos políticos y las prácticas de solidaridad.

En esta línea, estructuramos la tesis intentando resolver una serie de interrogantes que nos ayudaran a vislumbrar mejor esas lógicas internas. Nos preguntamos así, cómo surgió el movimiento de derechos humanos en Mar del Plata; por qué no se continuó con la experiencia de la primera organización de familiares de detenidos-desaparecidos surgida en la ciudad hacia 1976-1977; y cómo se explica el nacimiento y desarrolló de filiales en los años ochenta en la ciudad -en especial la filial de la organización Madres de Plaza de Mayo-. Asimismo, nos preguntarnos qué sujetos participaron en dicha filial en los años analizados, cuáles han sido las principales disputas y tensiones con el resto del movimiento de derechos humanos de la ciudad, cómo fue su relación con otras organizaciones políticas y sociales, y si tuvieron o no incidencia en las decisiones, estrategias y repertorios de acción de la Asociación, los cambios político-sociales acaecidos a nivel local y nacional.

Desde los años ochenta el movimiento de derechos humanos ha sido estudiado desde distintas disciplinas. En base a los diversos aportes, se puede decir que su surgimiento, acciones y efectividad se comprenden a partir de distintos niveles de estructuras de oportunidades locales, nacionales e internacionales y cómo estas interactúan y producen resultados concretos. De esta forma, consideramos que los estudios que hacen foco en lo local permiten complejizar las explicaciones sobre un tema específico, el cual, en el caso del movimiento de derechos humanos, ha sido estudiado, hasta hace algunos años, centrándose en la realidad capitalina, simplificando de esta manera lo acaecido en otros espacios. Esto es relevante si tenemos en cuenta que la escala en la cual actúan los actores sociales, construye sus límites de acción y sus identidades, por lo que cada localidad tiene su especificidad pese a los puntos de contacto con otras realidades. Los desarrollos locales presentan así diferencias en las periodizaciones, vínculos, desafíos, logros y experiencias respecto de los desarrollos que se presentan como nacionales. A partir de las nuevas investigaciones que hacen foco en el movimiento en 
distintos puntos del territorio nacional, es posible sostener que las formas y temporalidades del mismo en las distintas localidades variaron en función de las diversas tradiciones político- ideológicas que confluyeron en su seno, las estructuras de oportunidades políticas locales, los vínculos previos, la magnitud de la represión sufrida y los recursos movilizables. En este sentido, consideramos que los aportes potenciales de los estudios locales al estudio de la historia reciente en general y del movimiento de derechos humanos en particular, lo son si son puestos en diálogo con los producidos para otros espacios y escalas.

De esta forma, entendimos que la ciudad de Mar del Plata constituye una unidad de análisis pertinente para el estudio del movimiento de derechos humanos y para comprender los procesos de conformación de agrupaciones locales y de filiales y analizar el vínculo establecido con las organizaciones centrales y sus conducciones, en especial los grados de autonomía y de dependencia desarrollados. Consideramos que Mar del Plata y el movimiento que se conformó resultan una unidad de análisis pertinente por algunas de sus propias características, que justifican su observación, en pos de aportar a la construcción de una historia integral del movimiento: hacia 1980 era una de las ciudades con mayor población de la provincia -lo que permite analizar mejor el impacto del movimiento-. A la vez, se trata de una ciudad cabecera de Partido -por lo que tiene mayor relevancia política que otras de la provincia-. Asimismo, en los años '70 y '80 era una de las pocas ciudades universitarias de la Argentina, por lo que la ciudad contaba también con un actor estudiantil de relevancia. Resaltamos además el desarrollo de una economía que combinaba actividades vinculadas al turismo con otras industriales, en la que serán los actores vinculados a esta última los que se acercarán al movimiento, en especial tras la derrota en la guerra de Malvinas. Otra característica es la presencia significativa de la CNU en el ámbito universitario, los sindicatos y el poder judicial -recordemos que salvo en La Plata y Mar del Plata la organización no tuvo un peso significativo en otros lugares- cuya continuidad en esos espacios ya iniciado el proceso de democratización, generó sentimientos específicos en los militantes de las organizaciones de derechos humanos vinculados a la idea de impunidad, el miedo, la indignación y la impotencia. También destacamos el triunfo por primera vez en la ciudad del radicalismo en las elecciones municipales de 1983. Resulta relevante a su vez la cantidad de personas desaparecidas desde 1975 -entre 220 y más de 400 según los distintos listados conformados desde la dictadura-, mucho más alta que en otras ciudades o pueblos de la provincia, dado los niveles de movilización previos entre los trabajadores y los estudiantes. Otra característica es la intensa actividad que desplegó el movimiento de derechos humanos local, lo que llevó a que hacia 1979 los agentes de inteligencia de la policía bonaerense consignaran que la primera organización local constituía la comisión de familiares de mayor relevancia del interior de la provincia y a que sus acciones fueran catalogadas por los mismos como dentro de la actividad política de mayor importancia del Partido. A esto debe sumársele la gran cantidad de organizaciones que fueron surgiendo a lo largo de los años -filiales de APDH, LADH, Madres -Asociación y Línea Fundadora-, Familiares, Abuelas y posteriormente de la agrupación HIJOS en sus distintas vertientes- lo cual es relevante porque es evidente que no en todas las localidades de la Argentina se conformaron esa cantidad y diversidad de organizaciones, pese a las políticas de expansión territorial llevadas adelante por algunas de las mismas desde, al menos, principios de los años ochenta. A la vez, tuvimos presente que la Asociación Madres de Plaza de Mayo poseía, a mediados de los años ochenta, una veintena de filiales, algunas de las cuales se desvincularon de la conducción en los años noventa o principios de los 2000, mientras que la filial marplatense continúa bajo la conducción de la línea de Hebe Pastor de Bonafini -presidenta desde 1979-. Estas características, que hacen que consideremos a Mar del Plata como una unidad de análisis interesante, no hacen que perdamos de vista el hecho de que, al hacer foco en una localidad, no debe caerse en falsas especificidades y debe avanzarse en el camino del enfoque comparativo, todavía poco explorado pese a los importantes avances.

La tesis cuenta con dos grandes capítulos, antecedidos de una introducción en la que realizamos un balance del estado actual de los estudios en torno al movimiento de derechos humanos en general y de Madres de Plaza de Mayo en particular, indicando algunas tendencias y áreas de vacancia. En la misma reflexionamos además sobre los usos y potencialidades de la escala local, el concepto "movimiento" para dar cuenta de las 
luchas por los derechos humanos en la Argentina, y las particularidades del trabajo con testimonios para el estudio del pasado reciente.

En el primer capítulo, en el cual abordamos brevemente el contexto político-social local en que se constituyó y actuó la agrupación Madres, Familiares y Abuelas de Detenidos Desaparecidos de Mar del Plata, demostramos cómo la magnitud de la represión desplegada desde 1975 por la CNU, la policía y las FFAA contra los militantes de distintas agrupaciones de izquierda y peronistas -desapariciones forzadas, sustracción de la identidad de menores de edad, prisión política, tortura y asesinatos- llevó a que en la ciudad se conformara un grupo heterogéneo de ciudadanos marplatenses que se organizó en virtud de compartir una misma problemática, la desaparición de un familiar -el hermano, el cuñado, el esposo, el hijo, el nieto, el yerno-, y del fracaso en la búsqueda individual de respuestas. Esto no significa que todas las personas que tenían un familiar desaparecido se hayan volcado a la lucha colectiva. Así, analizamos los orígenes del movimiento de derechos humanos en la ciudad, a partir de la experiencia de la primera organización local de familiares y demostramos que la misma se conformó a partir de la pérdida particular de cada integrante entre 1975 y 1978 , por el rechazo que algunos sintieron en sus redes previas, por los contactos que a otros les facilitaron sus redes, por la falta de respuestas en las instituciones a las cuales recurrieron en un comienzo -las FFAA, el poder judicial y la iglesia católica-, por los encuentros en esos espacios, por los sentimientos de miedo y amenaza que provocaba continuar solos la búsqueda, por la decisión de unir su reclamo con el de otros en el marco de un contexto adverso y por el vacío y desarticulación de las agrupaciones políticas que dejó la magnitud de la represión. Dimos cuenta de que las principales acciones estuvieron orientadas a la difusión y denuncia de los crímenes cometidos en la cuidad, la solidaridad y los apoyos mutuos, y que tuvieron como objetivo visibilizar la represión, obtener información y matizar los efectos de dicha represión en los lazos sociales. Indicamos asimismo que una serie de elementos llevaron a que el grupo fuera tomando cada vez más conciencia de la necesidad de una mayor organización que derivó en cierta institucionalidad. Hemos considerado que dichos elementos fueron, por un lado, los consejos que les dieron tempranamente militantes locales del PST respecto a organizarse entre los familiares de los detenidos, y los vínculos tempranos del grupo con el padre Enzo Giustozzi, militante de la APDH. Por otro lado, la desaparición de una de las mujeres del grupo en 1977, tuvo un fuerte impacto, puesto que reveló los riesgos de la exposición. Especial atención le dimos a los vínculos con otras organizaciones de derechos humanos que actuaban en la capital del país como LADH, Madres de Plaza de Mayo -al menos desde 1978- y su subcomisión de abuelas, APDH -al menos desde 1979-, Familiares -al menos desde 1979-, y el CELS -al menos desde 1980-. Asimismo, consideramos fundamental los lazos construidos por fuera de las fronteras nacionales, al menos desde 1982. Así, observamos que participar en FEDEFAM les permitió obtener una visión más global de la problemática, compartir estrategias y visibilizar sus actividades a partir de los boletines, congresos y reuniones de dicha Federación. Otro elemento importante fue la necesidad de sistematizar los casos de desaparecidos de la ciudad frente a la visita de la CIDH en 1979 y el impacto de su informe publicado al año siguiente, que incluía el caso de una desaparecida de la ciudad. Por último, consideramos relevante la participación -desde el mismo año de inicio, en 1981- en los Encuentros Nacionales y las Marcha de la Resistencia de Madres de Plaza de Mayo, sin estar conformada aún la filial. Estos elementos dieron una mayor conciencia de la magnitud de la represión y de la necesidad de organizarse mejor colectivamente, para reducir los riesgos de la exposición pública y lograr los objetivos de saber qué había pasado con sus familiares y obtener justicia por los crímenes cometidos por la dictadura. Estos elementos impulsaron el inicio de un proceso de institucionalización o formalización del grupo a partir de 1982 que vimos presente en una serie de cambios: la conformación de una Comisión Juvenil de Apoyo y de una Comisión Jurídica que presentaba servicios múltiples; la disponibilidad de un espacio propio en pleno centro cívico y comercial; la estabilización del nombre en sus documentos, en la prensa y en los informes policiales; y la utilización de una hoja membretada para todo tipo de comunicaciones en la que se deja ver la disputa por los símbolos de legitimidad al interior del movimiento. Así, mostramos que a partir de cierta institucionalización de la agrupación y la necesidad de mantener un discurso unificado, 
se desataron una serie de debates internos que hicieron estallar la unidad construida durante la dictadura. De esta forma, el retorno a la institucionalidad democrática implicó la intensificación de las acciones, la participación de distintos actores políticos de la ciudad en las mismas y una mayor visibilidad mediática, pero también fragmentaciones a su interior.

Dimos cuenta de que esas divisiones se pueden entender si se tiene presente que fueron favorecidas por la rápida desilusión que vivió una parte del grupo respecto al gobierno de Alfonsín. La agrupación había depositado grandes expectativas en su figura -basadas en su participación en la APDH, su discurso rupturista y de reconstrucción democrática y fundamentalmente porque había dicho que había desaparecidos con vida- y había pensado en la democracia en sí como forma de obtener verdad y justicia por los crímenes cometidos. Así, a partir de 1984, el grupo sufrió una serie de aislamientos y fragmentaciones originados en distintas causas. Por un lado, se produjeron algunos alejamientos tras la desilusión generada por la no aparición con vida de los detenidos-desaparecidos de aquellos motivados sólo por la esperanza de recuperar al familiar. Por otro lado, se fragmentó por la especialización de las luchas originadas también por dicha evidencia, como encontrar a los niños secuestrados o nacidos en cautiverio, es decir los posibles "desaparecidos con vida”. Asimismo, jugaron un papel importante los enfrentamientos entre las personalidades más fuertes por su capacidad de liderazgo. Fundamental fue el peso de los posicionamientos que había que acordar en la nueva coyuntura en torno a las demandas -en especial la consigna de Aparición con vida-, las alianzas -en especial con el gobierno radical local-, y las estrategias -en especial la participación o no en la delegación local de la CONADEP-. Por último, no debe olvidarse la presión ejercida por la política de expansión territorial de otras organizaciones -en especial de Madres de Plaza de Mayo y APDH-.

En el segundo capítulo mostramos que la formación y el desarrollo de la organización Madres de Plaza de Mayo filial Mar del Plata se dio en la posdictadura a partir de dimensiones tanto locales como nacionales: por un lado, se debió a las divisiones producidas en esa primera organización de familiares de detenidosdesaparecidos a raíz de los mencionados debates y reposicionamiento tras la asunción de los gobiernos radicales elegidos democráticamente en 1983 en la ciudad, la provincia y la nación, sobre todo las relacionadas a cómo continuar en el nuevo contexto democrático, es decir, qué estrategias utilizar, con quién aliarse y qué consignas mantener. Por otro lado, se debió a la política de expansión de la Asociación Madres de Plaza de Mayo llevada adelante desde la dictadura y en disputa por el territorio con otras organizaciones como APDH, LADH y Familiares, y también como forma de afianzar su representatividad en un contexto a su vez de debate interno y de disputa del liderazgo al interior de la Asociación. De esta forma, un grupo de mujeres optó por conformar una filial de una asociación ya constituida, en vez de crear una nueva organización netamente local. Esta posición se vio favorecida por distintas razones. Por un lado, por lo potente que era simbólicamente el uso del pañuelo blanco sobre las cabezas para identificarse, y por la imagen fuerte de su presidenta, Hebe Pastor de Bonafini, que si bien en otros casos fue causal de rupturas, en otros favoreció la creación de delegaciones. Por otro lado, fue fundamental la constante organización o participación en acciones registradas por la prensa, el reconocimiento y legitimidad que poseía al interior del movimiento, el apoyo que recibía de juventudes políticas, su visibilidad a nivel internacional, y su postura crítica frente al gobierno de Alfonsín. Estas características hicieron que un grupo de mujeres se inclinara por la creación de una filial, esperando de esa forma que sus demandas fueran más visibles y legítimas y en vistas de que tenían posturas más cercanas que con el grupo original y que poseían un vínculo con la Asociación al menos desde 1978, descartando de esta forma cualquier tipo de interpretación basada en criterios económicos, es decir, formar una filial con el objetivo de alcanzar un sustento económico para sus acciones.

Sin embargo, vimos que las causas de la expansión de filiales de Madres durante los años ochenta no fueron las mismas en todas las localidades en las que se conformaron. En aquellas localidades en que la filial se formó durante la dictadura, las razones se encuentran cercanas a la necesidad de ocupar el espacio público y los consiguientes cuestionamientos respecto a la "inmovibilidad" de los organismos existentes y la ineficacia de las acciones. Por su parte, en las constituidas en la posdictadura, tuvo un mayor peso la disolución o 
debilidad de otras organizaciones de derechos humanos -en las que se percibían posturas moderadas-, las relaciones tempranas con la Asociación Madres de Plaza de Mayo entabladas a partir de viajes a la Capital Federal -pero también de la presidenta al resto de las provincias de la Argentina- y las críticas a algunas posturas de otros organismos, que impulsaron debates en torno a la CONADEP y la consigna "Aparición con vida". De esta forma, vimos que la opción por la acción directa propia de la Asociación es una de las causas en distintas localidades, pero que en la ciudad estudiada aquí no tuvo incidencia en la formación de la filial. Asimismo, en este capítulo analizamos la relación con otras organizaciones de la ciudad, con las demás organizaciones del movimiento de derechos humanos local y el vínculo con sus pares de la Capital Federal. Para ello consideramos algunos casos concretos de debates y tensiones que se generaron en los años ochenta, pero también manifestaciones de solidaridad al interior del movimiento frente a contextos adversos. En el marco de esas solidaridades, tensiones, luchas y disputas, vimos que se conformó una identidad política colectiva específica a lo largo de la segunda mitad de los años ochenta.

Como sucedió en otras localidades estudiadas por otros investigadores, como por ejemplo Córdoba, Santa Fe, Rosario, Tucumán o Neuquén, insistimos en que el movimiento de derechos humanos en Mar del Plata no fue un movimiento homogéneo, pero esa heterogeneidad no debe ser interpretada como inexistencia del movimiento. Por el contrario, y si tomamos como eje la composición del grupo, en el período estudiado la agrupación original estuvo integrada por familiares con distintas vinculaciones sanguíneas, con y sin experiencia política, algunos de los cuales sabían dónde militaba su familiar -lo que no implicaba necesariamente apoyarla- mientras que otros lo desconocían totalmente. La construcción de una identidad común -"ser familiar de detenido-desaparecido"- no pudo acabar con una variedad de identidades culturales, familiares y político-ideológicas que se entrecruzaban -y entrecruzan-a esa identidad común de militante por los derechos humanos con radio de acción en la ciudad de Mar del Plata. De esta forma, resulta un tanto paradójico que, cuando el movimiento comenzó a ser reconocido por otros sectores como un interlocutor válido y relevante, cuando comenzó a contar con la participación en sus actividades de agrupaciones estudiantiles, gremiales y juventudes políticas, y se hizo más fuerte el reclamo por verdad y justicia en la transición y la posdictadura, esas otras identidades previas basadas en intereses y experiencias diversas y disímiles, comenzaron a eclosionar y a producir reacomodamientos a su interior, produciendo divisiones que llevaron a la creación de filiales de organizaciones reconocidas de la Capital Federal -APDH, Madres de Plaza de Mayo y Abuelas de Plaza de Mayo- y con variada representación en otros puntos del país.

Así como no todas las personas que tenían un familiar desaparecido se organizaron colectivamente, es evidente que no todas las mujeres argentinas que tenían algún hijo detenido-desaparecido se organizaron en la Asociación Madres de Plaza de Mayo, así como no todas sus integrantes estaban enlazadas por ese vínculo primario. Varios autores han señalado que las respuestas más extendidas entre los familiares de detenidos-desaparecidos durante la última dictadura fueron, más que la lucha y la organización, la negación, el sentimiento de impotencia, la depresión, e incluso la enfermedad, la muerte o el suicidio, y que sólo fue una minoría la que decidió dar una respuesta política a la represión, es decir, que decidió asumir la dimensión política que implicaba la búsqueda del familiar iniciada en el contexto de dictadura. Debe tenerse en cuenta que en el camino de posicionamientos y definiciones, algunas mujeres-madres de detenidos-desaparecidos, optaron por seguir un camino de organización y lucha en otros organismos como Familiares de detenidosdesaparecidos o Abuelas de Plaza de Mayo. Las mujeres que optaron por organizarse en la Asociación Madres de Plaza de Mayo -que vimos que no necesariamente eran madres biológicas de un detenidodesaparecido-, lograron conformar una identidad y una memoria colectiva basada en los años de experiencia y lucha conjunta en torno a un discurso ético-político determinado y unas acciones colectivas acordes, basadas en consignas específicas que las diferenciaron del resto del movimiento de derechos humanos, en especial la negación a recibir reparaciones económicas por parte del Estado por la desaparición del familiar, la negación a la realización de homenajes póstumos a los detenidos-desaparecidos y la negación a llevar adelante exhumaciones de cadáveres NN con el fin de identificarlos. 
Por último, en las conclusiones, además de realizar un pequeño balance de la tesis, dimos cuenta de que pese a la creciente producción académica en torno a la historia reciente en general y al movimiento de derechos humanos en particular, aún existen perspectivas, aspectos, actores y lugares poco explorados. En esa línea, es evidente que esta tesis no agota las posibles investigaciones en torno al movimiento de derechos humanos en general y a su actuación en Mar del Plata en particular. En términos generales, aún restan conocer experiencias del movimiento -tanto dentro como fuera del país- y profundizar en los vínculos con formas previas de organización. Asimismo, carecemos de un análisis sistemático de las relaciones del movimiento de derechos humanos con el movimiento obrero, así como no existen trabajos que exploren si existe algún tipo de relación entre las primeras reacciones frente a la desaparición del familiar, la decisión de integrar una u otra organización y la clase social de pertenencia. Así, consideramos necesario seguir explorando las distintas experiencias del movimiento y realizar mayores comparaciones, con el fin de reducir los falsos excepcionalismos.

\section{BY-NC-SA}

\section{INFORMACIÓN ADICIONAL}

Defensa de tesis: 3 de julio de 2019

Director: Dr. Daniel Lvovich, Universidad Nacional de General Sarmiento, Argentina 